\title{
APLIKASI BEL SEKOLAH OTOMATIS BERBASIS ARDUINO DILENGKAPI DENGAN OUTPUT SUARA
}

\author{
Arie Linarta ${ }^{1}$, Nurhadi ${ }^{2}$ \\ ${ }^{1,2}$ Sekolah Tinggi Managemen Informatika dan Komputer (STMIK) Dumai \\ Jl.Utama Karya Bukit Batrem II Dumai-Riau kode pos 28811 \\ e-mail : arielinarta@mail.stmikdumai.ac.id
}

\begin{abstract}
ABSTRAK
Bel sekolah merupakan sebuah perangkat yang dibutuhkan disekolah sebagai media pendukung untuk menyampaikan informasi atau sebagai pemberitahuan pergantian jam kepada siswa dan guru. Namun masalah yang sering muncul adalah suara bel yang dihasilkan pada umumnya hanya sebatas bunyi buzzer yang tidak memiliki informasi tertentu dan sulit untuk dipahami, selain itu bel diaktifkan secara manual melalui tenaga piket yang bertugas untuk menyampaikan informasi dan membunyikan bel sekolah pada jam atau waktu tertentu. Aplikasi bel sekolah otomatis berbasis ARDUINO ini dilengkapi dengan modul DFPlayer mini yang mampu memainkan format file suara .MP3 atau.WAV, sehingga informasi yang disampaikan melalui bel dapat berupa suara menggunakan bahasa inggris dan bahasa Indonesia. Dengan kemampuan memainkan file suara dalam format .MP3 dan .WAV maka informasi yang disampaikan melalui bel dapat dengan mudah dipahami oleh seluruh stakeholder di sekolah.
\end{abstract}

Kata Kunci : Bel sekolah otomatis, microcontrollerArduino

\section{PENDAHULUAN}

Bel atau lonceng sekolah adalah suatau perangkat atau alat komunikasi yang sering ditemukan di sekolah. Perangkat ini merupakan alat bantu untuk memberikan instruktsi kepada seluruh murid dalam melaksanakan suatu kegiatan tertentu. Pada umumnya sekolah menggunakan lonceng yang terbuat dari bahan besi yang kemudian dipukul dengan teknik tertentu agar menghasilkan suara untuk menyampaikan informasi kepada murid sekolah, seperti 3x pukulan menandakan berbaris dihalaman dan sebagainya. Kemudian seiring dengan perkembangan teknologi, sudah banyak sekolah yang menggunakan bel listrik sebagai alternatif pengganti dari lonceng sekolah yang terbuat dari besi.

Latar belakang pemilihan judul ini adalah dengan mengamati secara langsung bel listrik yang digunakan disekolah. Perangkat bel listrik hanya mampu menampilkan suara buzzer atau serangkaian nada yang ada pada mesin bel, namun tidak memiliki arti atau informasi tertentu sehingga sulit untuk dimengerti oleh seluruh siswa maupun guru di sekolah. Berdasarkan kondisi tersebut tercetus ide untuk membuat sebuah aplikasi Bel Sekolah Otomatis Berbasis Arduino yang mampu menyampaikan informasi dalam bentuk file suara yang telah direkam dengan format file *.Mp3 dan *.WAV.

Melalui aplikasi bel sekolah otomatis berbasis ARDUINO yang dilengkapi dengan output suara ini, maka seluruh informasi yang dihasilkan oleh mesin bel dapat dengan mudah dipahami. Berikut ini beberapa contoh informasi file suara yang dimaksud :

1. Saat terjadinya pergantian jam

Disetiap pergantian jam pelajaran maka mesin bel akan memainkan file suara yang berisikan nada bell dan pemberitahuan pergantian jam sesuai jam pelajaran.

Contohnya :

"Saatnya jam pertama dimulai" atau "Saatnya jam kedua dimulai"

2. Saat jam istirahat

Disetiap memasuki jam istirahat maka mesin bel akan memainkan file suara yang berisikan nada bell dan pemberitahuan bahwa telah memasuki jam istirahat.

Contohnya : 


\section{INF O R M A I K A}

\section{Jurnal Informatika, Manajemen dan Komputer, Vol. 10 No. 2 , Desember 2018}

eISSN : 2580-3042

pISSN : 1979-0694

"Saatnya istirahat pertama" atau "Saatnya istirahat kedua"

3. Saat JamMasuk

Begitu juga saat jam masuk kelas, maka mesin bel akan memainkan file suara yang menginformasikan bahwa seluruh siswa agar memasuki kelasnya masing-masing.

Contohnya :

"Mohon perhatian seluruh siswa diharapkan memasuki kelas masing-masing, bapak dan ibu guru segera memasuki kelas".

Tujuan penelitian ini adalah untuk membuat perangkat teknologi tepat guna dalam bentuk mesin bel sekolah otomatis yang mampu menghasilkan output suara dengan format file .MP3 dan .WAV. Dengan demikian informasi yang dihasilkan mesin bel bisa disampaikan menggunakan berbagai jenis bahasa seperti bahasa Indonesia dan bahasa Inggris.

Manfaat dari penilitian ini adalah menghasilkan sebuah prototype mesin bel sekolah otomatis yang mampu menghasilkan pesan suara dalam format *.Mp3, dan *.WAV, sehingga informasi perubahan jadwal pelajaran dan informasi lainnya disekolah dapat dengan mudah dipahami oleh siswa/i dan guru.

\section{Landasan Teori}

a. Pengertian Sistem

Sistem dapat diartikan sebagai suatu kumpulan atau himpunan dari unsur, komponen, atau variabel yang teroganisir, saling berinteraksi, saling tergantung satu sama lain, dan terpadu (Al Fatta, 2007).

b. Sistem Pengendali

Sistem pengendalian adalah susunan suatu komponen yang dihubungkan sedemikian rupa untuk mengatur suatu kondisi agar menc apai kondisi yang diharapkan. Sistem pengendalian ini secara umum terdiri dari tiga elemen pokok, yaitu input, proses dan output. Output merupakan hal yang dihasilkan oleh kendalian, artinya yang dikendalikan. Sedangkan input adalah yang mempengaruhi kendalian, yang mengatur output (Ichwan, Husada, \& Rasyid, 2013).

c. Bel Sekolah

Bel sekolah merupakan salah satu instrumen penanda jam tertentu yang ada di sebuah lembaga pendidikan. Sejak zaman dulu telah mengenal bel itu secara sederhana seperti kentongan dan lonceng. Seiring dengan perkembangan zaman, saat ini ada yang namanya bell elektrik. Bel elektrik

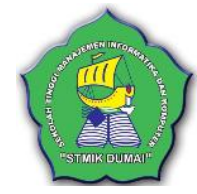

dibunyikan oleh petugas secara manual (Subianto, 2015).

d. Alokasi Waktu Sekolah

Pengaturan alokasi waktu untuk setiap mata pelajaran yang terdapat pada sistem semester ganjil dan genap dalam satu tahun ajaran dapat dilakukan secara fleksibel dengan jumlah beban belajar yang tetap. Satuan pendidikan dimungkinkan menambah maksimum empat jam pembelajaran per minggu secara keseluruhan. Pemanfaatan jam pembelajaran tambahan empertimbangkan kebutuhan peserta didik dalam mencapai kompetensi, di samping dimanfaatkan untuk mata pelajaran lain yang dianggap penting dan tidak terdapat di dalam struktur kurikulum. Perbedaan sistem paket dan sistem sks rata-rata 1 sks sama dengan 2 jam waktu pembelajaran pada sistem paket (Satria \& Yanti, 2017).

e. Microcontroller Arduino

Arduino UNO adalah sebuah board mikrokontroler yang didasarkan pada ATmega328. Arduino UNO mempunyai 14 pin digital input/output (6 di antaranya dapat digunakan sebagai output PWM), 6 input analog, sebuah osilator Kristal $16 \mathrm{MHz}$, sebuah koneksi USB, sebuah power jack, sebuah ICSP header, dan sebuat tombol reset.

Arduino UNO memuat semua yang dibutuhkan untuk menunjang mikrokontroler, mudah menghubungkannya ke sebuah computer dengan sebuah kabel USB atau mensuplainya dengan sebuah adaptor AC ke DC atau menggunakan baterai untuk memulainya (Adriansyah \& Hidyatama, 2013).

f. Visual Basic .Net

Aplikasi Visual Basic .Net dipaketkan pada aplikasi Microsoft Visual Studio 2008. Saat instalasi, pengguna bisa memilih programming language yang akan diinstal pada komputer. Aplikasi yang ada pada Visual Studio 2008 diantaranya adalah VB, C\# dan C++. Secara default, Visual Studio 2008 akan melakukan instalasi terhadap programming language yang ada, tetapi pengguna bisa memilih seluruh atau sebagian programming language tersebut diinstal pada computer (Komputer, 2010)

\section{METODOLOGI PENELITIAN}

Pada kegiatan penelitian ini secara garis besar terbagi menjadi 2 jenis sistem, yaitu sistem perangkat keras (hardware) dan sistem perangkat lunak (software). Dalam menyelesaikan penelitian ini penulis 
INFORM T IK A

Jurnal Informatika, Manajemen dan Komputer, Vol. 10 No. 2 , Desember 2018

eISSN : 2580-3042

pISSN : 1979-0694

menggunakan metode SDLC. Adapaun tahapan yang dilakukan pada metode SDLC ini adalah :

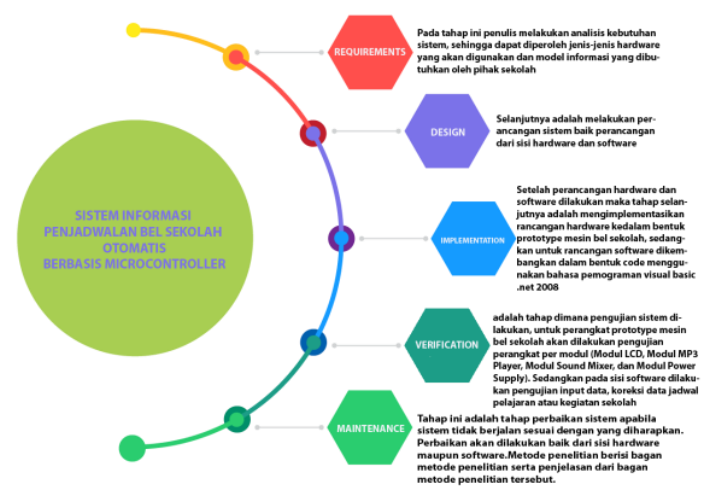

Gambar 1. Metode SDLC

Penjelasan dari metode SDLC di atas adalah sebagai berikut :

1) Requirements

Pada tahap ini penulis melakukan analisis kebutuhan sistem, sehingga dapat diperoleh jenis-jenis hardware yang akan digunakan dan model informasi yang dibutuhkan oleh pihak sekolah.

2) Design

Selanjutnya adalah melakukan perancangan sistem baik perancangan dari sisi hardware dan software.

3) Implementation

Setelah perancangan hardware dan software dilakukan maka tahap selanjutnya adalah mengimplementasikan rancangan hardware kedalam bentuk prototype mesin bel sekolah, sedangkan untuk rancangan software dikembangkan dalam bentuk code menggunakan bahasa pemograman visual basic .net.

4) Verification

Tahap verifikasi ini adalah tahap dimana pengujian sistem dilakukan, untuk perangkat prototype mesin bel sekolah akan dilakukan pengujian perangkat per modul (Modul LCD, Modul MP3 Player, Modul Sound Mixer, dan Modul Power Supply). Sedangkan pada sisi software dilakukan pengujian input data, koreksi data jadwal pelajaran atau kegiatan sekolah.

5) Maintenance

Tahap ini adalah tahap perbaikan sistem apabila sistem tidak berjalan sesuai dengan yang diharapkan. Perbaikan akan dilakukan baik dari

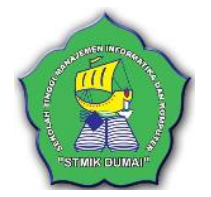

sisi hardware maupun software.Metode penelitian berisi bagan metode penelitian serta penjelasan dari bagan metode penelitian tersebut.

\section{HASIL DAN PEMBAHASAN}

Sistem bel sekolah otomatis yang akan dibangun secara garis besar terdiri dari beberapa sub system, diantaranya sub system aplikasi pengaturan jadwal, sub system perangkat control jadwal bel, sub system audio player, sub system pengeras suara (amplifier).

A. Implementasi Perangkat Keras

Berikut ini gambar blok diagram dari system informasi penjadwalan bel sekolah otomatis berbasis microcontroller yang akan dibangun.

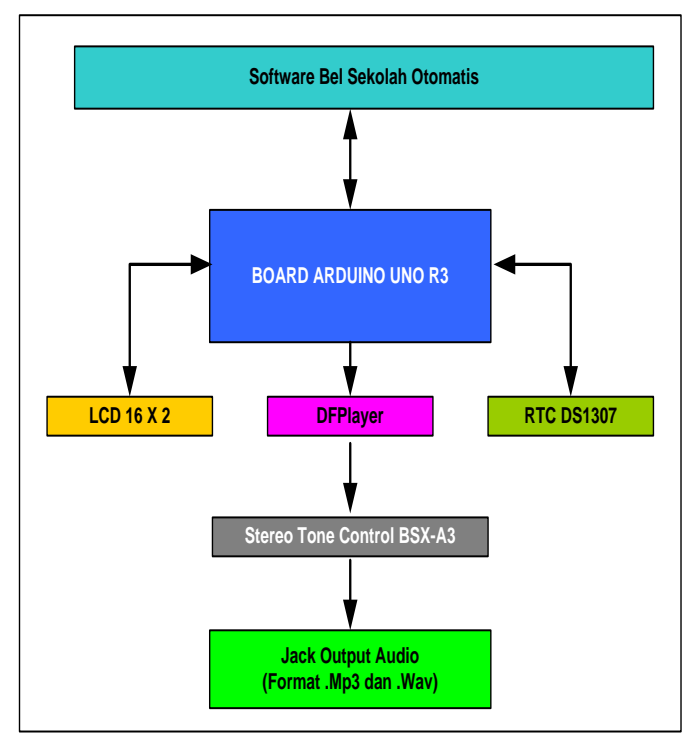

Gambar 2. Diagram Blok Sistem Kontrol Bel Sekolah Otomatis

Dari diagram blok gambar 2, dapat dijelaskan fungsi dari masing-masing blok komponen sebagai berikut :

a. Software Bel Sekolah Otomatis

Software bel sekolah otomatis ini berfungsi untuk mempermudah proses input atau setting jadwal bel sekolah, sehingga user tidak akan kesulitan dalam mensetting jadwal bel dalam jumah yang banyak.

b. Board Arduino

Board arduino uno R3 merupakan board microcontroller yang digunakan sebagai pemproses perangkat bel sekolah otomatis, dimana proses pencocokkan jadwal dan proses menampilkan informasi tanggal dan 
IN F ORM A I K A

Jurnal Informatika, Manajemen dan Komputer, Vol. 10 No. 2 , Desember 2018

eISSN : 2580-3042

pISSN : 1979-0694

waktu pada mesin bell dilakukan pada unit blok board arduino uno R3 ini.

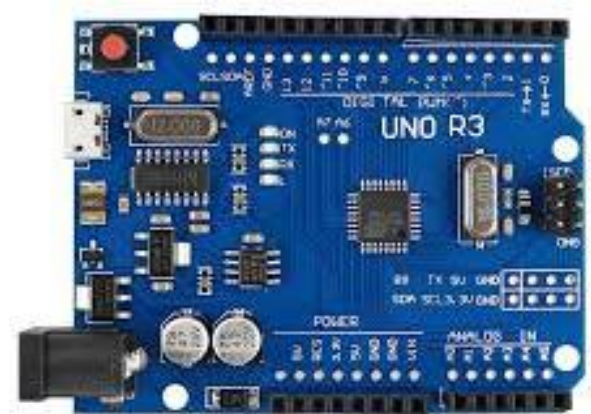

Gambar 3. Board Arduino Uno

c. LCD $16 \times 2$

Sementara blok LCD 16x2 merupakan sebuah perangkat LCD yang digunakan untuk menampilkan informasi tanggal dan waktu dari mesin bell.

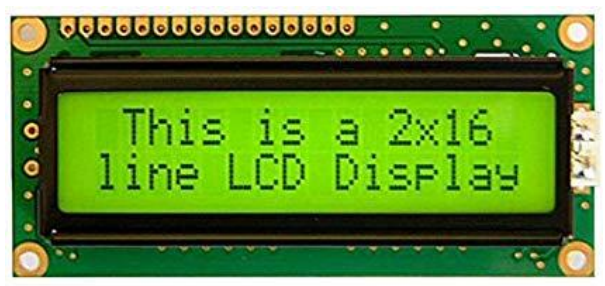

Gambar 4. LED $16 \times 2$

d. DFP Player

Mesin bel dapat memainkan file suara atau audio dalam format .mp3 dan .wav melalui komponen DFPlayer ini. Pada komponen DFPlayer ini terdapat sebuah mini SDCard yang akan diisi file-file suara atau audio bel sekolah seperti suara untuk menyampaikan jam masuk kelas, pergantian jam pelajaran, upacara dan file-file pendukung lainnya.

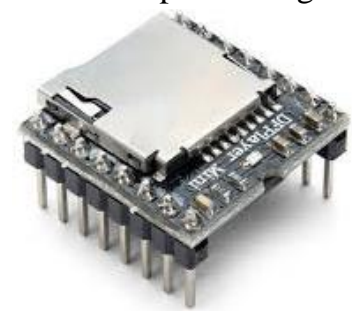

Gambar 5. DFPlayer mini

e. RTC DS1307

Blok komponen RTC DS1307 berfungsi agar mesin bel sekolah memiliki informasi tanggal dan waktu yang akurat serta mampu menyimpan memory tanggal dan waktu

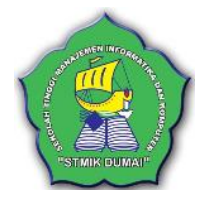

walaupun mesin bel dalam keadaan nonaktif.

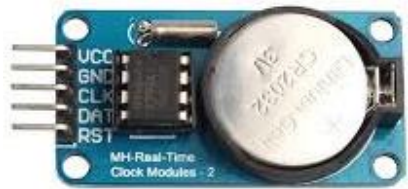

Gambar 6. RTC Modul

f. Stereo Tone Control BSX-A3

Hasil output suara dari komponen DFPlayer akan diteruskan sebagai input dari komponen stereo tone control BSX-A3 agar suara yang dihasilkan oleh mesin bell dapat decontrol dengan baik.

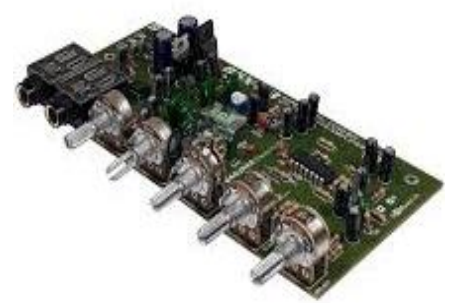

Gambar 7. Modul BSX-A3

g. Jack Output Audio

Jack Output Audio adalah sebuah interface standar yang digunakan untuk mempermudah penyambungan output suara yang dihasilkan oleh mesin bel sekolah otomatis ke perangkat amplifier disekolah sehingga suara bel dapat didengar langsung pada speaker corong atau speaker audio system milik sekolah.

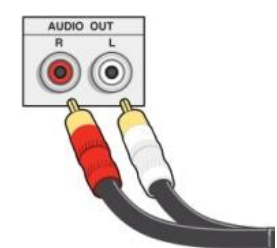

Gambar 8. Port Audio Out

Berdasarkan rancangan arsitektur komponen mesin bel sekolah otomatis sebelumnya, maka seluruh modul dan komponen tersebut dapat dirangkai dan digabung menjadi sebuah produk yang dapat dilihat pada gambar dibawah ini : 
INFORM T IK A

Jurnal Informatika, Manajemen dan Komputer, Vol. 10 No. 2 , Desember 2018

eISSN : 2580-3042

pISSN : 1979-0694

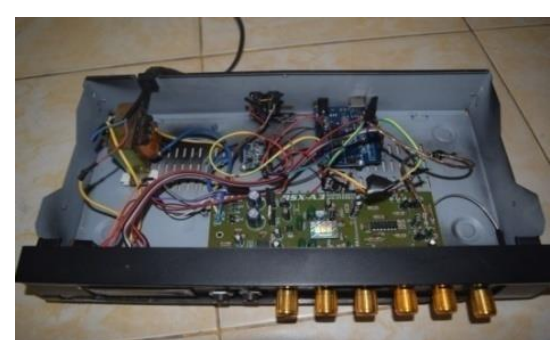

Gambar 9. Instalasi rangkaian mesin bel sekolah otomatis

B. Modul output suara

Untuk menghasilkan output suara .MP3 dan .WAV pada mesin bel, layout rangkaian yang digunakan adalah sebagai berikut:

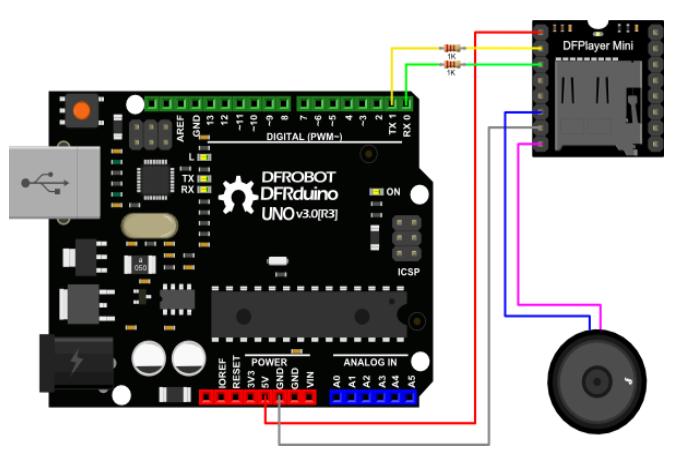

Gambar 10. Layout Rangkaian DFPlayer mini

Kemudian untuk rangkaian DFPlayer mini dan amplifier adalah sebagai berikut:

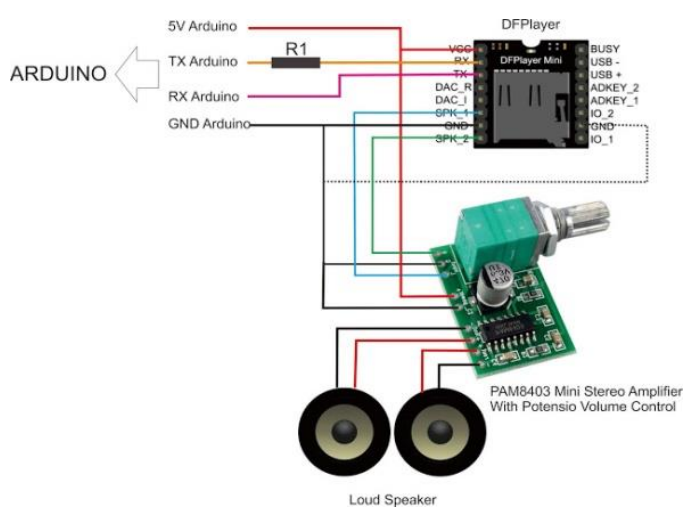

Gambar 11. Layout Rangkaian DFPlayer mini

Nama file suara yang bisa dimainkan pada modul harus disimpan dengan format angka yang terdiri dari 4 digit, dan diurutkan berdasarkan dari urutan terkecil hingga terbesar. Adapun tampilan format nama file

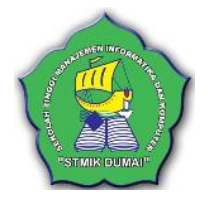

suara yang telah dicopy ke Memory Card adalah sebagai berikut :

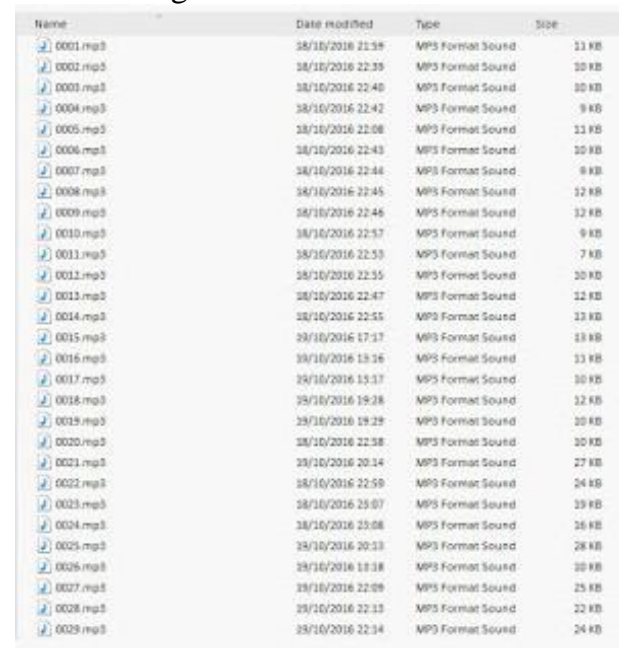

Gambar 12. Daftar nama file suara

C. Implementasi Perangkat Lunak

Proses pengaturan bel sekolah otomatis dimulai dengan menginput jadwal bel melalui aplikasi khusus bel sekolah otomatis yang berfungsi sebagai interface bagi operator untuk menyesuaikan waktu dan jadwal terhadap mesin bel sekolah otomatis. Setelah proses pengaturan waktu dan tanggal serta input jadwal bel dilakukan, maka selanjutnya operator dapat mentransfer jadwal yang telah dintetukan kedalam mesin bel sekolah otomatis melalui aplikasi tersebut, dan bel siap digunakan. Alur kegiatan penggunaan bel sekolah otomatis ini diperlihatkan pada gambar 5.1. dibawah ini :

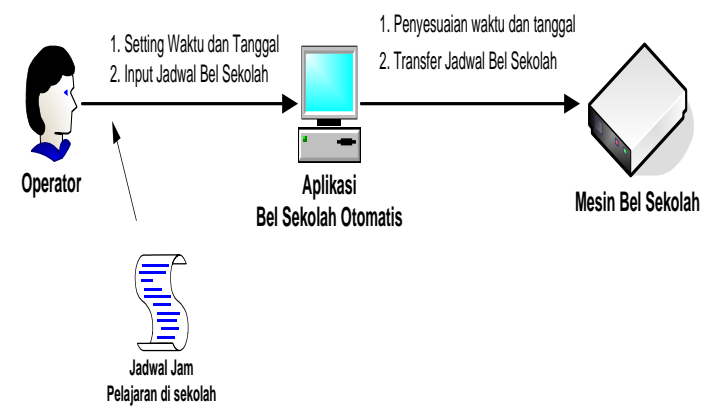

Gambar 13. Proses pengaturan bel sekolah otomatis

1) Proses input jadwal bel sekolah

Pada aplikasi bel sekolah otomatis proses input jadwal bel sekolah dapat dilakukan dengan mudah. Adapun tampilan dari aplikasi bel sekolah otomatis adalah sebagai berikut : 
INFORM T IKA

Jurnal Informatika, Manajemen dan Komputer, Vol. 10 No. 2 , Desember 2018

eISSN : 2580-3042

pISSN : 1979-0694

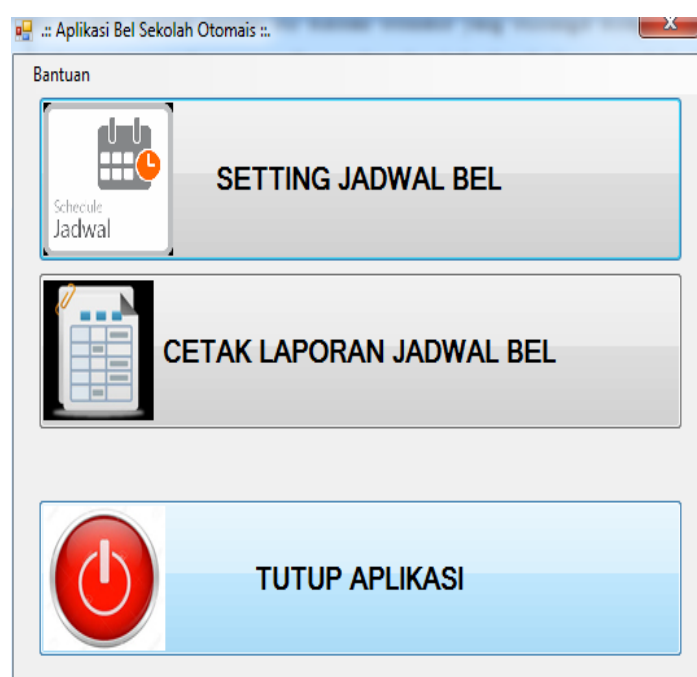

Gambar 14. Menu Utama Aplikasi Bel Sekolah Otomatis

Pada menu utama aplikasi bel sekolah otomatis ini terdapat pilihan "SETTING JADWAL BEL", "CETAK LAPORAN JADWAL BEL", dan "TUTUP APLIKASI". Untuk dapat melakukan proses input jadwal bel, maka operator dapat memilih pilihan "SETTING JADWAL BEL" maka aplikasi akan menampilkan form "Setting Jadwal Bel Sekolah" seperti yang diperlihatkan pada gambar 12 .

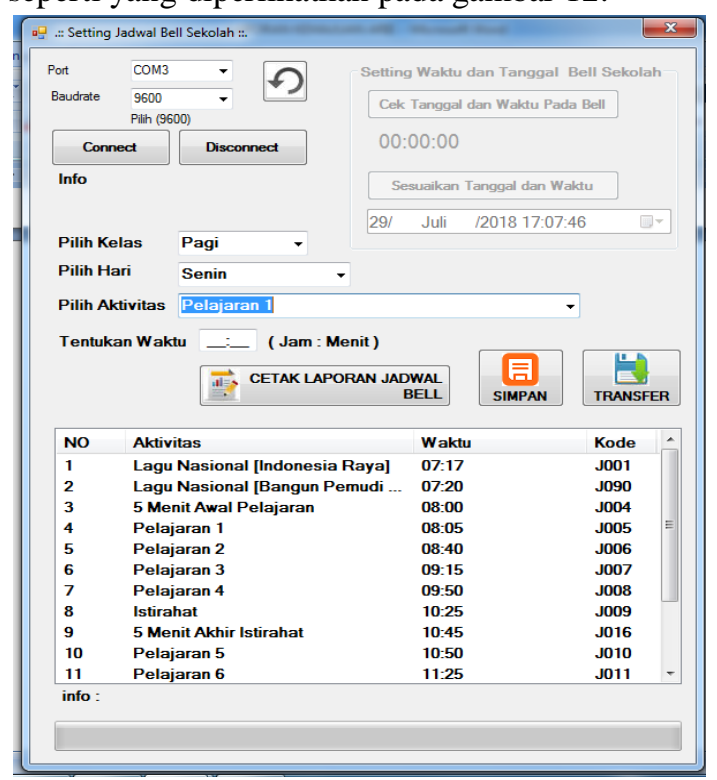

Gambar 15. Form Input Jadwal dan pengaturan waktu bel otomatis

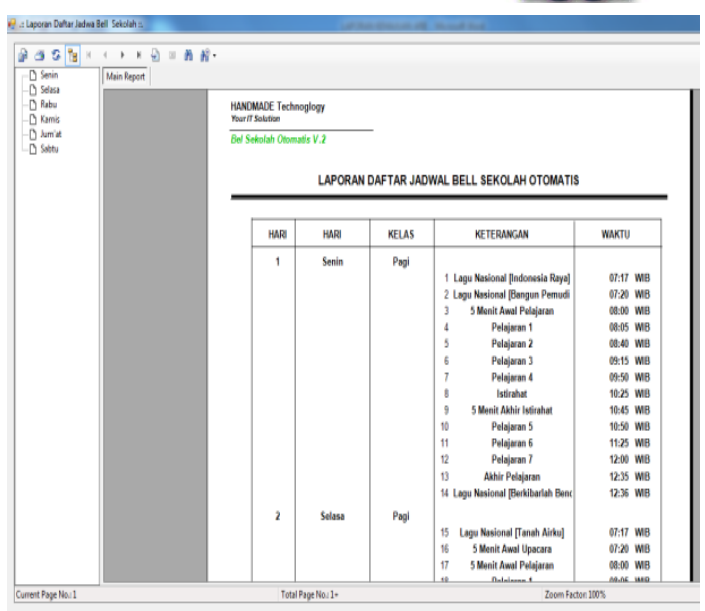

Gambar 16. Laporan jadwal bel sekolah otomatis.

2) Proses Upload Jadwal kedalam mesin bel sekolah otomatis

Setelah seluruh proses input data jadwal bel sekolah selesai dilakukan, maka langkah selanjutnya adalah mentransfer database jadwal sekolah yang tersimpan di PC/ Laptop kedalam mesin bel sekolah. Adapun proses transfer data jadwal dapat dilakukan dengan cara :

1. Hubungkan mesin bel melalui port USB ke PC/ Laptop kemudian

2. buka aplikasi bel sekolah otomatis.

3. Pada bagian menu utama klik "Setting Jadwal Bel"

4. Pada form setting jadwal bel pilih Port koneksi dan Klik tombol "Connect"

\section{믐 .: Setting Jadwal Bell Sekolah :..}

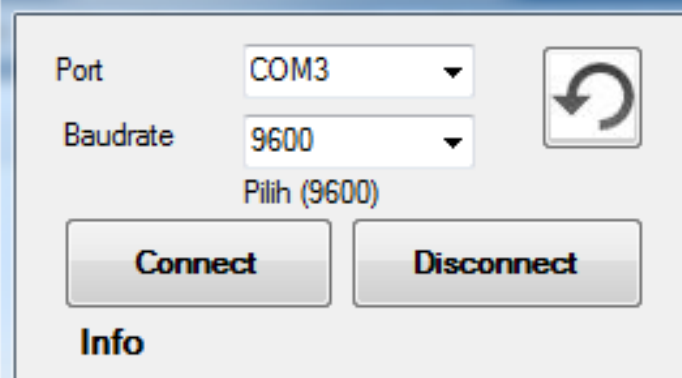

Gambar 17. Interface Konseksi Aplikasi ke Mesin Bel.

5. Setelah mesin terhubung ke PC, maka klik tombol "Transfer" untuk memulai proses transfer jadwal bel selesai. 
IN F ORM T I K A

Jurnal Informatika, Manajemen dan Komputer, Vol. 10 No. 2 , Desember 2018

eISSN : 2580-3042

pISSN : 1979-0694

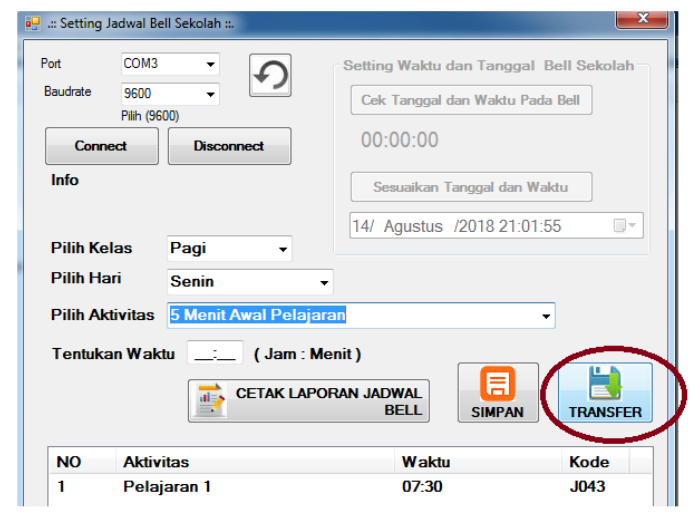

Gambar 18. Form Input dan Upload Jadwal Bel.

Jika proses transfer sudah selesai, maka tutup aplikasi, dan mesin bel siap digunakan.

\section{KESIMPULAN}

Berdasarkan rancangan dan hasil penelitian maka dapat disimpulkan bahwa sistem informasi penjadwalan bell sekolah otomatis berbasis microcontroller dapat berjalan dan berbunyi sesuai dengan jadwal yang telah ditentukan. Kemudian file suara yang telah disimpan kedalam Micro SD Card dapat dimainkan dengan baik dengan jenis format *.WAV dan *.MP3 melalui modul DFPlayer. Disamping itu dengan adanya aplikasi khusus yang dirancang sebagai interface mesin bell sekolah otomatis dapat memberikan kemudahan proses input atau pengaturan perubahan jadwal bell sekolah. Namun untuk saran pengembangan sistem kedepan agar hasil akhir atau finishing prototype mesin bell dapat dikemas dan di desain dengan tampilan box control panel yang lebih menarik.

\section{REFERENSI}

Adriansyah, A., \& Hidyatama, O. (2013). Rancang Bangun Prototipe Elevator Menggunakan Microcontroller Arduino ATMEGA 328P. Jurnal Teknologi Elektro, 4(3), 100-112.

Al Fatta, H. (2007). Analisis dan Perancangan Sistem Informasi. Yogyakarta: Andi Offset.

Ichwan, M., Husada, M. G., \& Rasyid, M. I. A. (2013). Pembangunan Prototipe Pengendalian Peralatan Listrik Pada Platform Android, 4(1), 13-25.

Komputer, W. (2010). Membuat Aplikasi Client Server dengan Visual Basic 2008. Jakarta: Media Kita.

Satria, D., \& Yanti, Y. (2017). Rancang Bangun Sistem Penjadwalan Bel Sekolah Berbasis Arduino Uno dengan Antarmuka Berbasis Web Menggunakan Ethernet Web Server. Serambi Engineering, II(3), 141-147. Retrieved from http://jurnalserambiengineering.net/wpcontent/uploads/2017/07/Rancang-BangunSistem-Penjadwalan-Bel-Sekolah-BerbasisArduino-Uno-dengan-Antarmuka-BerbasisWeb-Menggunakan-Ethernet-WebServer.pdf

Subianto, M. (2015). Sistem Bel Otomatis Terprogram Berbasis Rasberry Pi. Jurnal SMATIKA, 05, 5-12. 